\title{
Appalachlyan
}

B O O N , N O R T H C A R O L I N A

\section{Biblioteca Th'uruchapitas and Appalachian State University: Mutual Benefits of Sharing Culture, Resources, and Hospitality Between Two Sister Libraries}

\author{
By: Elizabeth Cramer, Gaby Vallejo Canedo, and Linda Veltze
}

\begin{abstract}
Biblioteca Th'uruchapitas is not limited to a defined space that contains books for children, but is a network of volunteers that engages with local schools, neighboring public libraries, non-profit organizations, and the general public. 1 Biblioteca Th'uruchapitas' many projects include "La Ronda," loaning books to publicschool teachers who, in turn, loan them to students; and "Para No Estar Solos," offering speech, reading, writing, and art sessions in conjunction with Centro de Apoyo Integral Carcelario y Comunitario (CAICC), a non-profit program for the children of inmates at the women's prison near Cochabamba. [...] of the Sister Libraries Program, Biblioteca Th'uruchapitas has received funding and materials from additional agencies that recognize the value of their work.
\end{abstract}

Cramer, E.E., Vallejo Canedo, G., and Veltze, L. (2015). Bibliotéca Th'uruchapitas and Appalachian State University: Mutual benefits of sharing culture, resources, and hospitality between two Sister Libraries. Bookbird, 53(1), 76-83. 


\section{Children \& \\ Their Books}

\section{Biblioteca Th'uruchapitas and}

Appalachian State University: Mutual Benefits of Sharing Culture, Resources, and Hospitality
Between Two Sister Libraries Elizabeth Cramer, Gaby Vallejo Canedo, and Linda Veltze

\section{Project Strategies}

Biblioteca Th'uruchapitas is Bolivia's first true children's library, founded by Bolivian educator and author Gaby Vallejo. Along with a group of seven founding members that proudly bear the title Mujeres Peligrosas (dangerous women) due to their progressive ideas about education, Vallejo provides library and educational services to the children and youth of Cochabamba, Bolivia. Biblioteca Th'uruchapitas is not limited to a defined space that contains books for children, but is a network of volunteers that engages with local schools, neighboring public libraries, non-profit organizations, and the general public. ${ }^{1}$ Biblioteca Th'uruchapitas' many projects include "La Ronda," loaning books to public-school teachers who, in turn, loan them to students; and "Para No Estar Solos," offering speech, reading, writing, and art sessions in conjunction with Centro de Apoyo Integral Carcelario y Comunitario (CAICC), a non-profit program for the children of inmates at the women's prison near Cochabamba.

In 1998, Linda Veltze, a library sci- ence faculty member at Appalachian State University, met Vallejo and together they formed a partnership between Biblioteca Th'uruchapitas and Appalachian State. This partnership was formally designated as a Sister Libraries Program by the White House Millennial Commission in 2000. The original intent of the partnership was to get sorely needed children's books to Bolivia, but it soon became clear that the program offered additional benefits to both Th'uruchapitas and Appalachian State. In 2001, a group of study-abroad students from Appalachian State's Department of Human Development and Psychological Counseling agreed to carry donated books to Bolivia in their backpacks, eliminating the need for costly postage. Upon their return, the students were markedly impressed and transformed by their experience with Biblioteca Th'uruchapitas. They were deeply moved by the dedication of Vallejo and the Mujeres Peligrosas, who often take public buses to local schools, transporting boxes of books to distribute to teachers. The students developed a new under- 
standing of the importance of reading and literacy when they witnessed the tears of Gaby and other Th'uruchapitas founding members upon receiving so many new and beautiful books.

After this first student trip to Bolivia, the focus of the partnership changed to a broader mutually beneficial exchange of opportunities. Appalachian students and faculty gained a great deal from interaction with another culture and group of devoted volunteers. The partnership began to draw interest and involvement from Appalachian State graduate and undergraduate programs, the University Libraries, the local community, and K-12 schools throughout North Carolina.

\section{Required Intercultural Skill Set}

Intercultural skills central to the success of this Sister Libraries Program are the ability to recognize and respect the personality and culture of each country. The partnership has been built on the exchange of information in order to learn each other's stories, customs, and cultural practices. Participants recognize the importance of understanding the reality of the other in order to create shared successful projects and support, implement, evaluate, and maintain them. Robert Sanders, Associate Dean of Graduate Studies at Appalachian State and frequent faculty leader for service projects in Bolivia, emphasized the importance of communicating with Biblioteca Th'uruchapitas to understand the reading preferences of educators and young readers in Bolivia: "We ask students to collect books to donate to the Biblioteca, but we don't always know what they want or need. Often, we purchase or collect books that our own students enjoy, but may not be appreciated by Bolivian children due to cultural references unique to American life. We need to find ways of being more sensitive to the specific needs and interests of the children in Bolivia who will read these books."

For the partnership to succeed, the leaders had to devise creative methods to communicate in Spanish and English. The key players drew on their language skills and developed a process in which individuals write to each other in their native languages. Vallejo, Veltze, and others have sufficient knowledge of the second language to understand what is written. This process allows individuals to fully express themselves in their primary language, while comprehending communication in a second language. This process is often aided by online translators or bilingual colleagues and acquaintances. This same principle works in face to face discussions with partners contributing or offering interpretation in both English and Spanish. A limited personal knowledge of the second language becomes much more substantial when combined with the limited personal knowledge of another individual. As a consequence, two semi-fluent speakers, working together, are able to have engaged and expanded conversations.

\section{Challenges and Successes}

Biblioteca Th'uruchapitas has benefited from this association with Appalachian State through numerous international service-learning projects. For over a decade, students have been raising money and gathering books for Biblioteca Th'uruchapitas. Recently, one library science class led by Robert Sanders raised over $\$ 4000$ and 
collected 1600 Spanish-language or bilingual books to hand-deliver to Biblioteca Th'uruchapitas. Many Appalachian students involved in the service-learning project were school media coordinators in the region who, in turn, got their K-12 students involved in fundraising efforts. Currently, Biblioteca Th'uruchapitas has made approximately 10,000 books available to the children of Cochabamba, of which an estimated 5000 were donated by students and faculty of Appalachian State.

As a result of the Sister Libraries Program, Biblioteca Th'uruchapitas has received funding and materials from additional agencies that recognize the value of their work. One big success for the program was receiving the International Board of Books for Young People (IBBY) Asahi Reading Promotion Award for making a lasting contribution to reading promotion to children and young people. The $\$ 10,000$ award, along with money raised by Appalachian State and K-12 schools in North Carolina, helped Biblioteca Th'uruchapitas purchase a new site for its central library headquarters. Th'uruchapitas was also fortunate to receive a donated van to help reach children in the areas surrounding Cochabamba. Following a visit to Boone, North Carolina, by Vallejo and other Th'uruchapitas founding members, the Rotary Club took an interest in the Bolivian library and donated the "bibliobus."

Appalachian State has also reaped rewards from the partnership. Numerous Appalachian State classes and "Alternative Spring Break" groups have traveled to Bolivia to visit Biblioteca Th'uruchapitas. As interest in international service-learning opportunities grows among faculty, students, and parents, Biblioteca Th'uruchapitas

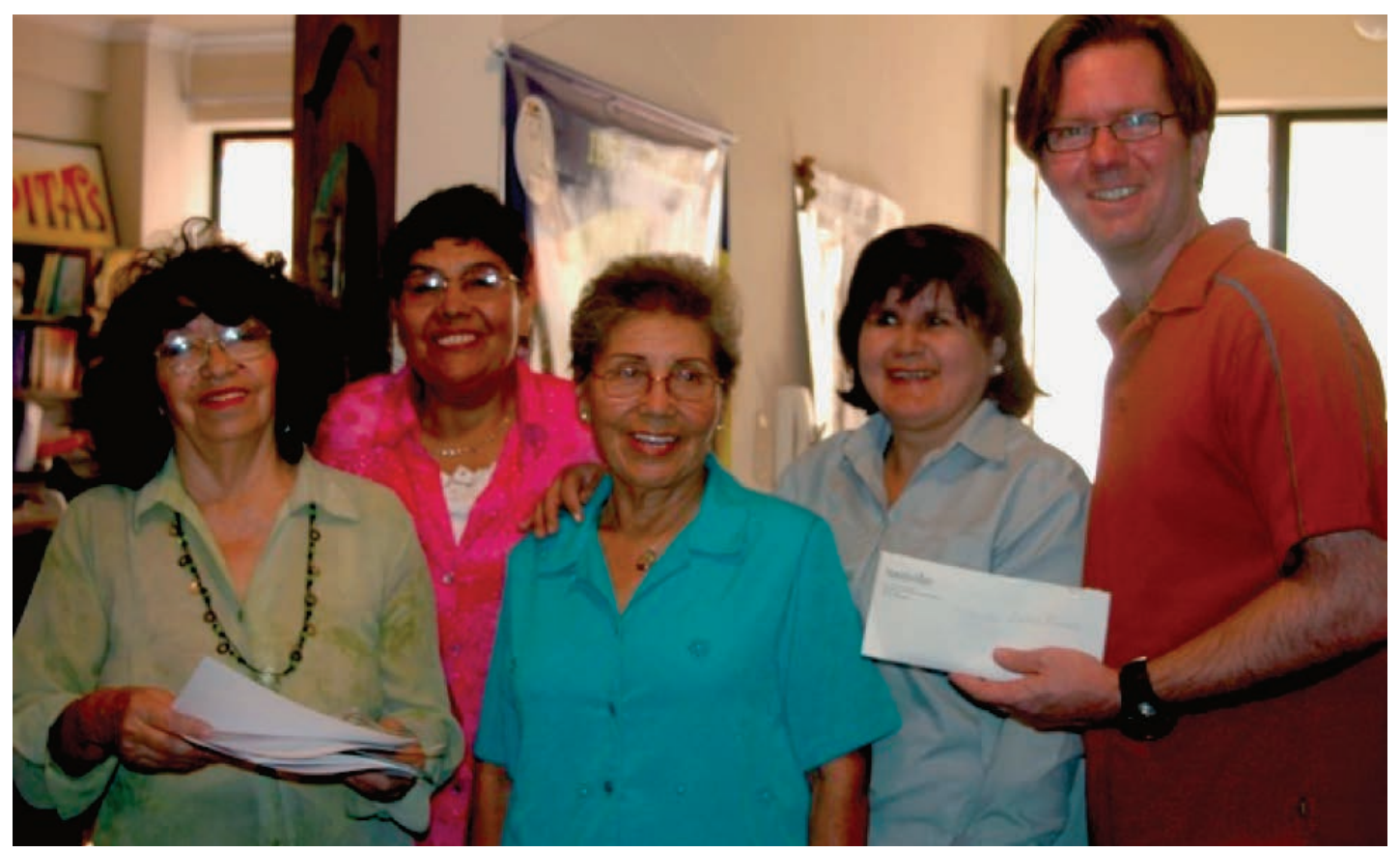

Gaby Vallejo, Lidia Coca, Casilda Sempertegui, Betzabé Cárdenas (Mujeres Peligrosas) with Robert Sanders, presenting fundraising donations from his library science students. (Credit: Robert Sanders) 


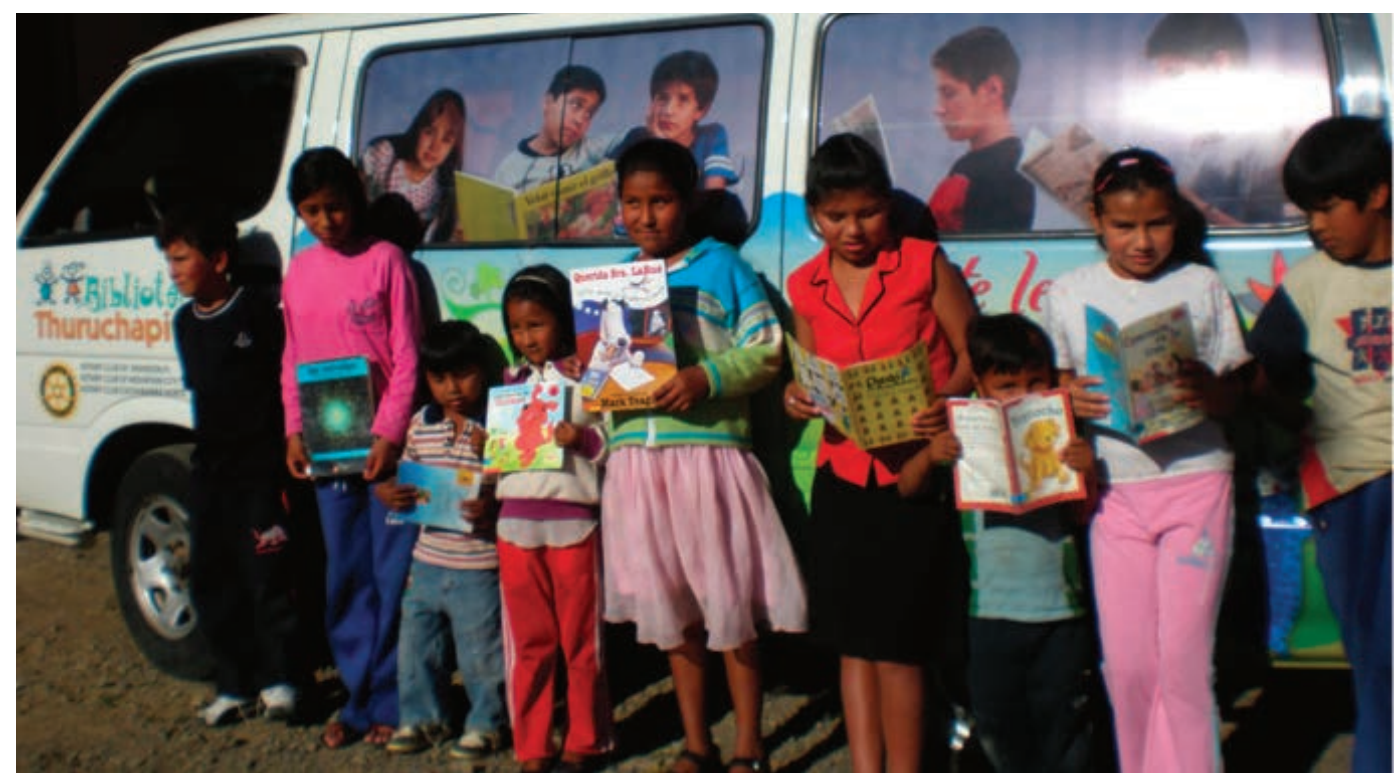

Young readers in front of the bibliobus. (Credit: Gaby Vallejo)

has proven to be an invaluable cultural-exchange partner. Appalachian students traveling to Bolivia increase their global awareness by experiencing life outside the United States and learning about Bolivian culture. For library science students in particular, Vallejo and founding members have demonstrated how creativity in reading promotion can maximize precious library resources and get books to children and how having a vision can enrich one's work. In times of limited budgets in the U. S., North Carolina librarians have witnessed Th'uruchapitas' success with no regular budget-only creativity and determination.

One recent success involved Sara Rhyne, a former Appalachian State library science graduate student who visited Biblioteca Th'uruchapitas as part of a service project in 2010. After talking with Vallejo and founding members about favorite books in the collection, she became aware that many were self-published and contained stories about Cochabamba and Bolivia. From this experience, Rhyne developed the desire to capture and disseminate local stories in other areas of the world. She connected with World Reader, an organization that publishes local stories, downloads them onto Kindle readers, and distributes these readers to children in SubSaharan Africa. Subsequently, Rhyne has traveled twice to Africa to train students and teachers on using these Kindle readers to access entire libraries of resources.

Many successes are of a humanitarian nature. The program has created an intercultural bond between two agencies in separate countries based on knowledge and mutual respect. The relationship allows Appalachian State and Th'uruchapitas to learn more about cultures outside their own, reaching out to discover and embrace differences and similarities. Many people involved with the Sister Libraries Program had the opportunity to visit the partner country and actually live in "otherness." A true indicator for success is that the pro- 
Bolivia expected to see economic differences between the U.S. and Bolivia yet were surprised by the relative wealth of the Bolivian people in terms of family, community, and culture.

On a recent trip lead by faculty member Keith Davis from Appalachian State's Department of Human Development and Psychological Counseling in May 2012, students wrote of their experiences at Biblioteca Th'uruchapitas on a blog created by the study abroad group. ${ }^{2}$ They expressed surprise that books simply were not available to children and youth in Bolivia, either through schools or public libraries. They were moved by the excitement generated by books among the children at Biblioteca Th'uruchapitas. They also wrote about the strikes in Bolivia at the time of their visit, conditions of the orphanages and other shelters in the area surrounding Cochabamba, and their new appreciation of the value of their own education.

Faculty partners from Appalachian State have never felt the need to offer formal professional development to Vallejo and volunteers at Biblioteca Th'uruchapitas. Instead, partners have worked together informally to share ideas, leaving both sides empowered to adopt concepts and innovations that are beneficial and relevant to their cultures, norms, and practices. Vallejo and several founding members have twice visited Boone, most recently in 2007. During their stays, they engaged in a wide variety of activities highlighting the Appalachian culture, visited local sites, public and school libraries, and spoke to audiences at Appalachian State and area schools, business associations, and community groups.

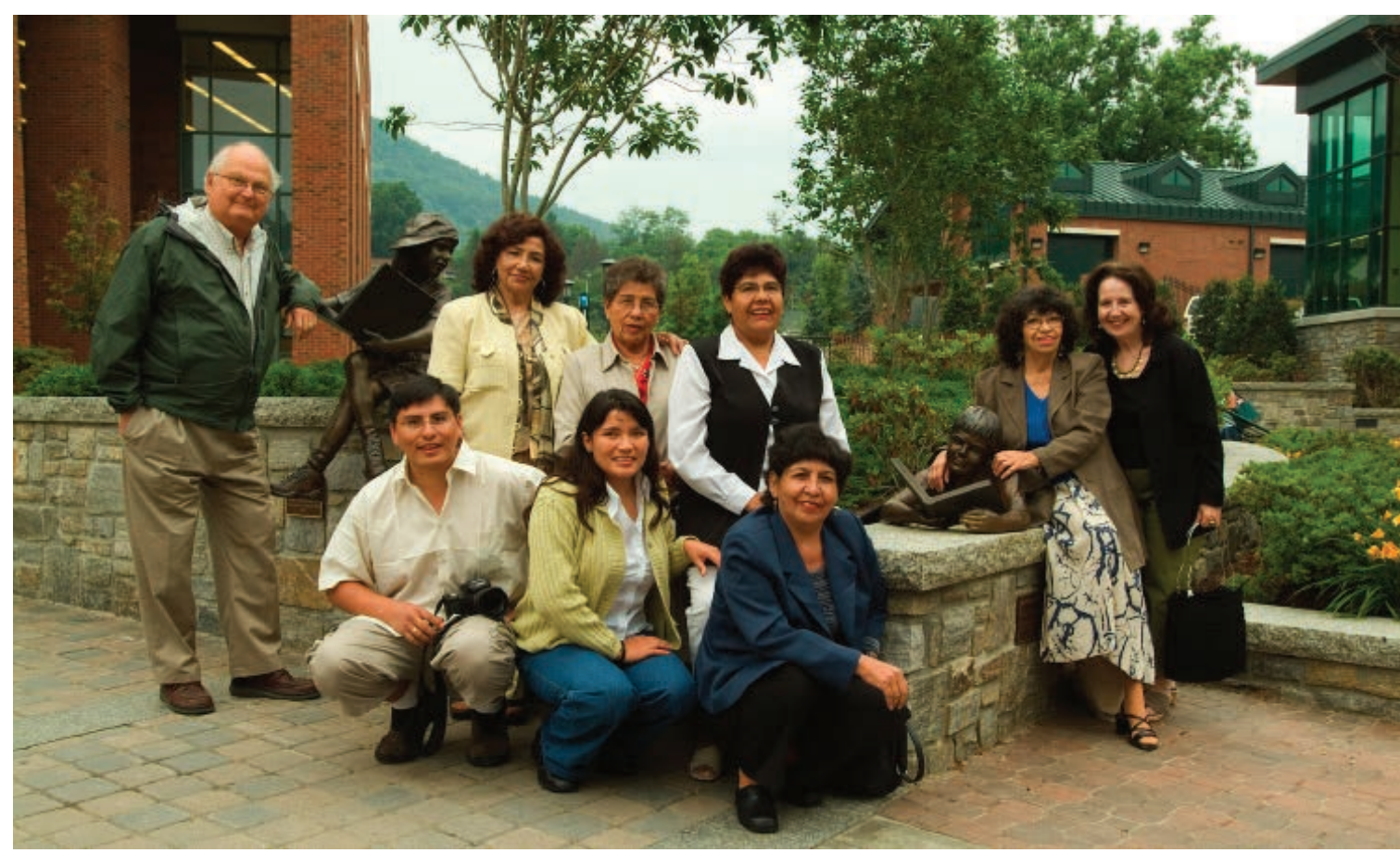

Th'uruchapitas volunteer teachers visit Appalachian State in 2007. Gaby Vallejo and Linda Veltze are on the right. (Credit: Mike Rominger) 
Appalachian State's students and faculty in the library science program and other programs across campus have benefitted from the international and intercultural relationships by learning from the founders of Biblioteca Th'uruchapitas.

These Bolivian educators place a high value on professional development in education, sponsor children's literature conferences in Bolivia, and travel to other conferences around the world as personal resources permit. They have never allowed their limited budget to limit the vision or breadth of their work.

\section{Educative Dialogues}

Veltze has conducted many discussions with library science students about libraries and life in Bolivia that would have never occurred without the connection with Biblioteca Th'uruchapitas. In a country where the gross national income (GNI) is a little more than $\$ 2000$ per year, ${ }^{3}$ a book that costs $\$ 25$ is equal to one-sixth of an average monthly salary. Not only does this highlight the differences between the two countries, but also challenges the idea of lending libraries in Bolivia as compared to their counterparts in the United States.

Another conversation was sparked by Th'uruchapitas' engagement with Centro de Apoyo Integral Carcelario y Comunitario (CAICG), a non-profit program that provides activities, educational opportunities, and a safe space for children of inmates at the women's prison. Even though Bolivia passed a law to abolish the practice of children living inside prisons with their incarcerated mothers, funds were never appropriated to create a viable alternative. The fact of young children sleeping in prisons is eye-opening for U. S. students and leads to interesting discussions about society, universal education, and public assistance.

Dialogues about Bolivian culture and libraries are facilitated at regional K-12 schools with the help of Bolivian Kits, a product of the collaboration. These kits include Bolivian cultural items such as clothing, musical instruments, toys, and books. With assistance from the Instructional Materials Center in the Appalachian State Library and funding provided by the University Friends of the Library, these items have been selected by the staff of Biblioteca Th'uruchapitas for their authenticity, placed in easy-to-carry containers, and made available to regional K-12 teachers and other educators. These kits are used in media centers and classrooms to teach cultural diversity and Bolivian culture and to inform about library resources in Bolivia and the special role played by Biblioteca Th'uruchapitas.

Information about the Th'uruchapitas-Appalachian Sister Libraries Program has been disseminated through several venues including conferences and publications. Every two years, Gaby Vallejo and Linda Veltze have been able to meet at the international IBBY Conference held in different locations around the world. Through presentations, they have shared their experience with others who may be interested in creating similar partnerships. In addition, the partnership has been publicized in numerous articles, presentations, interviews, blogs, and poster sessions, including a presentation at the American Library Association Annual Conference, as well as an article in ALA International Leads. 


\section{Post-Project Takeaways:}

Sister Libraries Programs can expand beyond the partners for support and participation

The Th'uruchapitas-Appalachian Sister Library Program reaches beyond two libraries and affects children, educators, and civic groups in both North Carolina and Bolivia. All types of libraries that participate in Sister Libraries Programs, including public, university, and media centers, can expand fundraising and multicultural awareness into the larger community, gathering support from a wide variety of participants.

\section{Sister Libraries Programs can be mutually beneficial}

Veltze's original vision was to deliver donated children's books from the United States to Bolivia. It was soon evident that
Appalachian State had much to gain from this partnership because of study abroad and service-learning projects in Bolivia. Vallejo and the founding members of Th'uruchapitas have served diligently as welcoming and tireless hosts for numerous Appalachian students and faculty.

\section{The success of a Sister Libraries} Program depends on dedicated individuals

With Veltze's retirement from Appalachian State, there is concern about the continuation of the program. Individuals on the Appalachian campus will need to assume leadership roles in recognition of the numerous opportunities it offers students and faculty to develop global awareness and personal development.

1 Biblioteca Th'uruchapitas. Retrieved 31 May 2013, www.librarythuruchapitas.org.

2 Boliviajournal. Retrieved 29 May 2013, Boliviajournal.wordpress.com.

3 World Bank Data: Bolivia. Retrieved 22 May 2013, http://data.worldbank.org/country/bolivia. 
Reproduced with permission of the copyright owner. Further reproduction prohibited without permission. 